\title{
Edukasi Penggunaan Antibiotika, Obat Keras, dan Over The Counter Medicine sebagai Upaya Pengendalian Resistensi dan Misused Drug di Kolom VIII GMIM Jemaat Victory Minanga Indah Kota Manado
}

\author{
Jainer P. Siampa ${ }^{1}$, Hosea J. Edy ${ }^{2}$ \\ ${ }^{1,2}$ Program Studi Farmasi, Fakultas Matematika dan Ilmu Pengetahuan Alam, \\ Universitas Sam Ratulangi Manado, 95115, Sulawesi Utara, Indonesia \\ Penulis korespondensi : Jainer Pasca Siampa, Program Studi Farmasi FMIPA \\ Universitas Sam Ratulangi \\ Email : jainerpsiampa@unsrat.ac.id
}

\begin{abstract}
ABSTRAK
Obat adalah zat kimia yang bersifat racun, namum dalam jumlah tertentu dapat memberikan efek yang baik bagi tubuh. Efek preventif dan kuratif yang bisa dihasilkan dengan mengonsumsi obat, membuat masyarakat sangat sering menggunakan obat untuk pengobatan sendiri (swamedikasi). Kenyataan yang ditemukan adalah masyarakat tidak memiliki informasi yang cukup tentang obat untuk menjamin keamanan dan keselamatan mereka. Hal ini pun terjadi pada masyarakat yang termasuk dalam Kolom VIII GMIM Victory Minanga Indah Kelurahan Malalayang II Kecamatan Malalayang Kota Manado Sulawesi utara sehingga perlu dilakukan edukasi. Kegiatan ini bertujuan untuk memberikan edukasi yang tepat tentang obat keras, antibiotika, obat bebas, dan swamedikasi sehingga dapat mengendalikan resistensi dan penyalahgunaan obat. Pemahaman yang benar tentang obat adalah racun akan membuat masyarakat lebih berhati-hati menggunakannya. Metode pelaksanaan adalah penyuluhan, studi kasus, dan diskusi. Capaian dari kegiatan ini adalah peningkatan pemahaman anggota masyarakat yang terukur dari hasil studi kasus dan diskusi. Masyarakat dapat dengan benar memecahkan kasus yang ada sehingga dapat disimpulkan bahwa kegiatan edukasi berhasil dengan baik dan masyarakat dapat menyampaikan informasi penting kepada keluarga dan masyarakat sekitar.
\end{abstract}

Kata kunci : Antibiotika; Edukasi obat; obat keras; OTC Medicine; Resistensi; Misused drug

\section{PENDAHULUAN}

\section{Analisis Situasi}

Peningkatan status kesehatan suatu bangsa merupakan perhatian khusus bagi setiap pemerintahnya, termasuk di Indonesia, Pemerintah lewat Kementerian Kesehatan terus berupaya agar status kesehatan masyarakat Indonesia terus membaik. Kemenkes telah melakukan Riset Kesehatan Dasar yang dilaksanakan setiap 5 tahun untuk mengetahui kondisi kesehatan masyarakat secara holistik. Data di bidang Farmasi salah satunya yaitu jumlah rumah tangga (RT) yang menyimpan obat untuk pengobatan sendiri (swamedikasi). Sejumlah 103.860 atau 35,2\% dari 294.959 RT di Indonesia menyimpan obat untuk swamedikasi. Dari $35,2 \%$ ini, RT yang menyimpan jenis obat keras sejumah $35,7 \%$ dan antibiotika $27,8 \%$. Adanya obat keras dan antibiotika untuk swamedikasi merupakan indikator penggunaan obat yang tidak rasional. Selain itu ada juga RT yang menyimpan sisa obat dari penggunaan sebelumnya yang tidak dihabiskan. Bila jenis obatnya adalah antibiotika maka sudah dipastikan terjadi penyalahgunaan karena seharusnya antibiotika ini dihabiskan agar tidak meningkatkan prevalensi resistensi. Selain itu proporsi penggunaan obat yang paling besar adalah golongan obat bebas (Over the counter/ OTC) sebasar $82 \%$. Proporsi penduduk Indonesia yang mengobati diri sendiri dengan membeli obat ke toko atau warung tanpa resep dokter adalah 26,4\% (Kemenkes, 2013; Dirjen Binfar, 2008). Hasil riset menunjukkan bahwa masyarakat banyak yang menyimpan obat di 
rumah baik itu obat bebas (OTC), antibiotika, dan obat keras. Hal ini disebabkan karena masyarakat kurang mengetahui jenis dan kategori obat yang telah ditetapkan (Rahayuda, 2016).

Pemerintah juga menggalakkan program 5T untuk penggunaan antibiotika yang bijak yaitu tidak membeli antibiotika sendiri (Tanpa resep dokter), tidak menggunakan antibiotika untuk selain infeksi bakteri, tidak menyimpan antibiotika di rumah, tidak memberi antibiotika sisa kepada orang lain, dan tanyakan pada apoteker informasi obat antibiotika (Yuliati, 2018). Hal ini masih belum dilakukan oleh masyarakat terbukti dengan adanya hasil riskesdas 2013, bahwa masyarakat di Sulawesi Utara sejumlah $37,3 \%$ masih menyimpan obat di rumah dan $81,4 \%$ diantaranya adalah antibiotika (Kemenkes, 2013). Namun bukan hanya di Indonesia, penggunaan antibiotika yang tidak rasional juga menjadi masalah global karena dibeberapa negara juga ditemukan penggunaan tanpa peraturan yang ketat sehingga dapat dibeli seperti obat bebas tanpa resep dokter yang berujung kepada penggunaan yang tidak sesuai dan berujung pada peningkatan resistensi (Ventola, 2015).

Selain antibiotika, obat keras dan obat bebas (OTC) juga sangat tinggi pemakaiannya dalam swamedikasi sehingga umum terjadi kesalahan penggunaan. Misalnya, masyarakat mengonsumsi obat dengan merek dagang berbeda tapi memiliki kandungan yang sama atau mengonsumsi obat yang berbeda kandungan tapi memiliki efek farmakologi yang sama. Bukan hanya terjadi pemborosan, tapi berakibat fatal untuk kesehatannya. Penggunaan obat yang rasional harus tepat diagnosis, tepat indikasi penyakit, tepat pemilihan obat, tepat dosis, tepat penilaian kondisi pasien, waspada terhadap efek samping obat, efektif, aman, mutu terjamin, terjangkau, tepat tindak lanjut, tepat penyerahan obat, pasien patuh terhadap perintah pengobatan (Dirjen Binfar, 2008).

\section{Kelompok Masyarakat Kolom VIII GMIM Jemaat Victory Minanga Indah}

Kelurahan Malalayang II Kecamatan Malalayang Kota Manado Provinsi Sulawesi Utara merupakan masyarakat perkotaan dengan kesibukan yang cukup tinggi. Lokasinya berdekatan dengan fasilitas kesehatan primer yaitu Puskesmas Minanga, namun karena jumlah antrian yang cukup panjang, masyarakat cenderung enggan kesana dan memilih melakukan swamedikasi untuk penyakit yang ringan atau sering dialami karena mudahnya mengakses apotek dan warung obat. Tapi ternyata, pada praktek swamedikasi, mereka belum sepenuhnya mengetahui kondisi penyakit dan obat yang harus dikonsumsi. Masyarakat belum memahami mengenai penyakit yang membutuhkan obat keras dan antibiotika sehingga kerap kali menggunakannya pada kasus yang tidak seharusnya menggunakan jenis obat ini. Masyarakat juga belum memahami mengenai bahaya resistensi yang akan terjadi bila penggunaan antibiotika yang tidak sesuai. Kebanyakan dari mereka akan menghentikan konsumsi antibiotika saat merasa baikan. Begitu pula dengan golongan obat bebas (over the counter) yang bisa ditemukan di toko atau apotek, para mitra hanya menggunakan berdasarkan iklan atau informasi yang mereka dapatkan dari kerabat sehingga sering terjadi penyalahgunaan obat (misused drug) misalnya menggunakan obat dengan merek dagang berbeda namun memiliki kandungan yang sama, menggunakan obat dengan kandungan yang berbeda tapi memiliki efek yang sama, dan menggunakan obat yang tidak sesuai dengan indikasi penyakit.

\section{Tujuan dan Manfaat Kegiatan}

Kegiatan edukasi ini bertujuan untuk meningkatkan pemahaman kelompok masyarakat kolom VIII GMIM Victory Minanga Indah Manado tentang antibiotika, obat keras, dan obat bebas agar dapat mengendalikan kejadian resistensi dan penyalahgunaan obat. Masyarakat yang hadir diharapkan dapat menjadi pengguna obat yang 
benar dan dapat pula mengedukasi keluarga di rumah dan masyarakat sekitar.

\section{METODE PELAKSANAAN}

\section{Sasaran Kegiatan Pengabdian}

Mitra pada kegiatan ini adalah anggota kelompok masyarakat usia dewasa, dalam hal ini pemuda dan orang tua yang sudah memiliki pengalaman menggunakan obat sendiri maupun obat yang diresepkan oleh dokter untuk keluarga. Kondisi ini memungkinkan untuk dilakukan edukasi agar pemahan yang keliru tentang penggunaan obat selama ini dapat diluruskan dan masyarakat ini dapat menggunakan obat dengan benar selanjutnya.

\section{Lokasi Kegiatan Pengabdian}

Kegiatan dilakukan di Kolom VIII GMIM Victory Minanga Indah, Kelurahan Malalayang II, Kecamatan Malalayang, Kota Manado.

\section{Metode yang Digunakan}

Metode pelaksanaan kegiatan ini adalah:

1. Memberikan penyuluhan kepada kelompok masyarakat dengan topik bahasan antara lain:
a. Definisi sehat dan sakit dengan tujuan agar masyarakat paham kondisi yang membutuhkan pengobatan
b. Pengertian dan syarat-syarat swamedikasi
c. Penggolongan obat
d. Resistensi antibiotika
e. Penyalahgunaan Obat

2. Studi kasus untuk mengetahui tingkat pemahaman masyarakat tentang materi yang diberikan.

3. Sesi tanya jawab tentang kondisi yang dialami masyarakat seputar penggunaan obat.

\section{HASIL DAN PEMBAHASAN}

Kegiatan pengabdian ini telah dilaksanakan pada hari Rabu, tanggal 21 Agustus 2019 mulai pukul 19.30 di tempat pertemuan kolom VIII di Kelurahan Malalayang II, Kecamatan Malalayang, Kota
Manado. Penyuluhan/ Kegiatan edukasi dihadiri oleh 30 orang masyakat dewasa (tidak termasuk anak-anak). Kegiatan dibagi menjadi 3 bagian yaitu pemberian penyuluhan, studi kasus, dan tanya jawab.

Penggolongan obat berdasarkan Permenkes No.917/1993 adalah (1) Obat bebas dengan logo lingkaran hijau dengan garis tepi berwarna hitam. Disebut juga over the counter (OTC ) medicine dan dapat dibeli secara bebas tanpa resep dokter. Contoh: Parasetamol, Antasida Doen, Neurobion; (2) Obat bebas terbatas dengan logo lingkaran biru dengan garis tepi berwarna hitam. Termasuk OTC tapi dengan beberapa peringatan tertentu. Contoh: OBH Combi, CTM, Neo Napacin; (3) Obat Keras dengan logo lingkaran merah, tepi berwarna hitam, dan ada huruf K. Hanya bisa dibeli di apotek dengan resep dokter. Contoh: Amoxicillin, obat hormon, dan semua bentuk injeksi; (4) Obat Narkotika adalah obat yang berasal dari tananaman atau bukan tanaman, baik sintesis maupun semi sintesis yang dapat menyebabkan penurunan atau perubahan kesadaran, hilangnya rasa, mengurangi sampai menghilangkan rasa nyeri dan menimbulkan ketergantungan (Depkes RI, 2007).

Secara umum cara penggunaan obat yang benar adalah minum obat sesuai petunjuk/ aturan yang terdapat dalam kemasan obat/ brosur, Penggunaan obat tidak untuk pemakaian secara terus menerus, Bila terjadi efek samping segera hentikan penggunaan dan hubungi dokter atau Apoteker, Hindarkan menggunakan obat orang lain walaupun gejala penyakit sama, Dapatkan informasi obat yang lebih lengkap pada Apoteker ( Depkes RI, 2007; BPOM, 2005)

Drug misuse (penyalahgunaan obat) didefenisikan sebagai penggunaan obat yang tidak sesuai dengan aturan hukum ataupun aturan pemakaian sehingga dapat menyebabkan efek negatif atau menbahayakan pasien (National Collaborating Center for Mental Health, 2008). Penyalahgunaan obat juga termasuk penggunaan OTC yang melebihi dosis dan terlalu lama dibanding dengan jumlah yang 


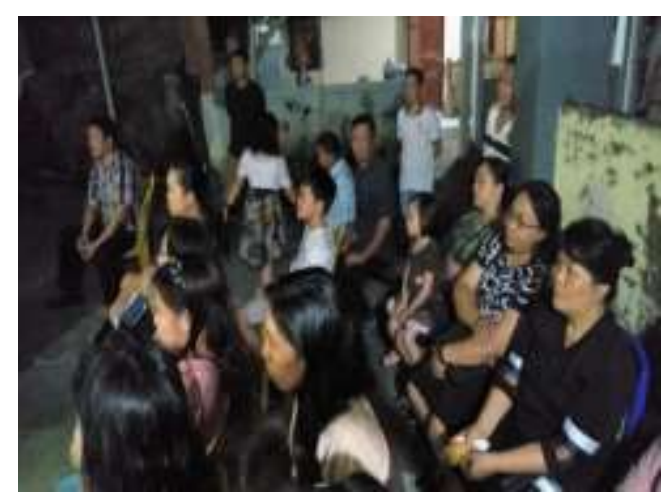

Gambar 2. Warga mendengarkan materi penyuluhan

berdampak pada tidak efektifnya obat antibiotika untuk menangani infeksi tertentu sehingga membutuhkan pengendalian resistensi. Pengendalian resistensi antimikroba adalah aktivitas yang ditujukan untuk mencegah dan/atau menurunkan adanya kejadian mikroba resisten. Pengendalian dilakukan dengan cara mengendalikan berkembangnya mikroba resisten melalui penggunaan antibiotika secara bijak yaitu dengan cara penggunaan yang rasional (Menkes RI, 2015).

Masyarakat sangat antusias mengikuti sesi penyuluhan ini yang terlihat dari antusiasmenya pada sesi tanya jawab. Masyarakat memberikan pertanyaan seputar materi yang diberikan dan juga menanyakan permasalahan terkait obat yang pernah mereka alami.

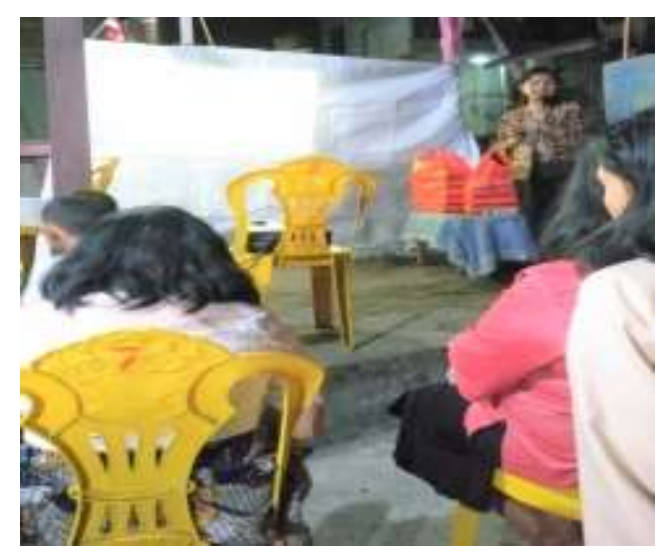

Gambar 1. Sesi pemberian penyuhan 


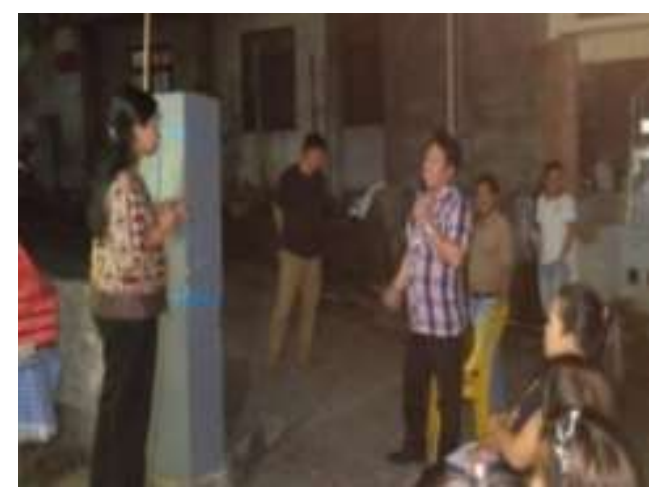

Gambar 4. Sesi tanya jawab

\section{KESIMPULAN DAN SARAN}

\section{Kesimpulan}

1. Edukasi obat antibiotika, obat keras, dan Over the counter medicine dapat menambah wawasan masyarakat dalam melakukan swamedikasi.

2. Pemahaman yang benar tentang cara penggunaan obat yang benar dapat mencegah terjadinya resistensi antibiotika dan penyalahgunaan obat (misused drug)

\section{Saran}

Kegiatan edukasi tentang penggunaan obat dilakukan secara berkala pada kelompok masyarakat agar pemahaman yang ada dapat menjadi habituasi yang baik.

\section{UCAPAN TERIMAKASIH}

Terimakasih kepada Kementerian Riset, Teknologi, dan Pendidikan Tinggi Republik Indonesia melalui Lembaga Penelitian dan Pengabdian Masyarakat Universitas Sam Ratulangi (LPPM- Unsrat) yang telah membiayai kegiatan Program Kemitraan Masyarakat tahun pendanaan 2019.

Terima kasih kepada masyarakat Kolom VIII GMIM Victory Minanga Indah Manado yang telah menerima tim pengabdian untuk melaksanakan kegiatan penyuluhan.

\section{DAFTAR PUSTAKA}

Badan Pengawas Obat dan Makanan. 2005. Cara Penggunaan Obat yang Benar. Available www.pom.go.id/mobile/index.php/vie w/berita/75/Cara-Penggunaan-Obat-yang-Benar.html

Departemen Kesehatan RI, 2007. Pedoman Penggunaan Obat Bebas dan Bebas Terbatas. Direktorat Jenderal Bina Kefarmasian dan Alat Kesehatan. Jakarta

Dirjen Bina Kefarmasian dan Alat Kesehatan. 2008. Modul 1 : Materi Pelatihan Peningkatan Pengetahuan dan Keterampilan Memilih Obat bagi Tenaga Kesehatan.

Kementerian Kesehatan. 2013. Riset Kesehatan Dasar (Riskesdas). Badan Penelitian dan Pengembangan Kesehatan Kementerian Kesehatan RI. Jakarta

Menteri Kesehatan RI. 2015. Peraturan Menteri Kesehatan Republik Indonesia Nomor 8 Tahun 2015 tentang Program Pengendalian Resistensi Antimikroba di Rumah Sakit. Jakarta

National Collaborating Center for Mental Health. 2008. Drug Misuse : Psychosocial Interventions. The British Psychological Society \& The Royal College of Psychiatrists. Leicester UK

Rahayu, IGS. 2016. Identifikasi Jenis Obat Berdasarkan Gambar Logo Pada Kemasan Menggunakan Metode Naive Bayes. Jurnal Sisfo Vol. 06. No. 01(2016) 17-32

Smith SM, Dart RC, Katz NP, Paillard F, Adams EH, Comer SD, Degroot A, Edwards RR, Haddox JD, Jaffe JH, et al. 2013. Classification and Definition of Misuse, Abuse, and Related Events in Clinical Trials : ACTTION Systematic Review and Recommendations. Available https://www.ncbi.nlm.nih.gov/pmc/arti cles/PMC5460151/

Ventola, CL. 2015. The Antibiotic Resistance Crisis. Part 1 : Causes and Threats. Pharm Thera 40(4): 277-283 
Jurnal Pengabdian Multidisiplin

Yuliati, R. D. Landasan Pelaksanaan Program Pengendalian Resistensi Antimikroba di Indonesia. Jakarta 